\title{
Pancreatic Medullary Carcinoma
}

National Cancer Institute

\section{Source}

National Cancer Institute. Pancreatic Medullary Carcinoma. NCI Thesaurus. Code C95466.

A pancreatic ductal adenocarcinoma characterized by poor differentiation and a prominent syncytial growth pattern. The prognosis is more favorable compared to conventional pancreatic ductal adenocarcinoma. 